\title{
Pengembangan Telehealth "SIPISPeKa" sebagai Solusi Mensukseskan Program Indonesia Sehat dengan Pendekatan Keluarga (PIS-PK)
}

\section{Development of Telehealth "SIPISPeKa" as a Solution Program Indonesia Sehat Pendekatan Keluarga (PIS-PK)}

\author{
Warjidin Aliyanto $^{1}$, Lisa Suarni ${ }^{2}$, Sono $^{3}$, Alex Iskandar Hajar ${ }^{4}$ \\ ${ }^{1}$ Jurusan Kebidanan, Politeknik Kesehatan Tanjung Karang, Indonesia \\ ${ }^{2,3,4}$ Program Studi Keperawatan Kotabumi, Politeknik Kesehatan Tanjung Karang, Indonesia
}

\section{ARTICLE INFO}

\section{Article history}

Received date

18 Mar 2021

Revised date

22 Mar 2021

Accepted date

08 Apr 2021

\section{Keywords:}

Application;

Health family index;

Telehealth.

\section{Kata kunci:}

Aplikasi;

Indeks Keluarga Sehat;

Telehelath.

\begin{abstract}
ABSTRAK
There is a phenomenon in Indonesia that shows that the use of telehealth is not optimal in hypertension management in Indonesian health services which has an impact on cost efficiency both for the government and patients in the community. Based on this, researchers are interested in researching the use of telehealth in PISPK-based homecare services in health services in Indonesia. The purpose of this study was to assess the quality of Telehealth Applications in the Program Indonesia Sehat Pendekatan Keluarga (PISPK). The research design was the development of a telehealth prototype named SIPISPeKa which was by the needs of the Community Health centers in providing health services for families in the category of troubled families in the PISPK assessment. Research respondents are families with the unhealthy category in the Healthy Family Index in Tanjung Aman Village, Kotabumi Selatan District was 147 respondents. Processing and data analysis in this study using univariate analysis using frequency distribution. SIPISPeKa as a telehealth/telehealth media is declared worthy of being assessed from 4 aspects of assessment, namely: telehealth media principles, governance, web-based communication media, and relevance to the PISPK program. Assessors' comments and suggestions for SIPISPeKa include the need to improve the SIPISPeKa application to make it friendlier, easier to use and more able to replace the presence of health workers in families with low IKS scores.
\end{abstract}

\begin{abstract}
Fenomena di Indonesia menunjukkan belum optimalnya penggunaan telehealth dalam manajemen hipertensi di layanan kesehatan Indonesia yang berdampak pada cost efficiency baik itu pada pemerintah ataupun pasien di masyarakat. Berdasarkan hal tersebut maka peneliti tertarik untuk melakukan penelitian tentang penggunaan telehealth dalam pelayanan homecare berbasis PIS-PK dilayanan kesehatan di Indonesia. Tujuan penelitian ini adalah menilai kualitas aplikasi telehealth dalam Intervensi Program Indonesia Sehat dengan Pendekatan Keluarga (PIS-PK). Desain penelitian adalah pengembangan prototype telehealth yang diberi nama SIPISPeKa yang sesuai dengan kebutuhan Puskesmas dalam memberikan pelayanan kesehatan bagi keluarga dalam kategori Keluarga bermasalah dalam penilaian PIS-PK. Responden penelitian adalah keluarga dengan kategori tidak sehat dalam Indeks Keluarga Sehat di Kelurahan Tanjung Aman Kecamatan Kotabumi Selatan yang berjumlah 147 orang. Pengolahan dan analisis data pada penelitian ini menggunakan analisis univariat menggunakan distribusi frekuensi. Hasil penelitian menunjukkan bahwa penilaian oleh ahli media dan ahli substansi maupun pengguna, SIPISPeKa sebagai media telehealth dinyatakan layak dinilai dari 4 aspek penilaian yaitu: kaidah media telehealth, tata kelola, media komunikasi berbasis web dan relevansi dengan program PIS-PK. Komentar dan saran penilai terhadap SIPISPeKa antara lain perlu adanya penyempurnaan aplikasi SIPISPeKa agar lebih bersahabat, lebih mudah digunakan dan lebih dapat menggantikan kehadiran petugas kesehatan pada keluarga dengan nilai IKS yang rendah.
\end{abstract}

Corresponding Author:

Lisa Suarni

Program Studi Keperawatan Kotabumi, Politeknik Kesehatan Tanjung Karang, Indonesia

Email: lisakausar@yahoo.co.id 


\section{PENDAHULUAN}

Kesehatan merupakan hak asasi manusia dan salah satu unsur kesejahteraan yang harus diwujudkan sesuai dengan cita-cita bangsa Indonesia berdasarkan Pancasila dan UndangUndang Dasar Negara Republik Indonesia Tahun 1945. Pembangunan nasional yang digagas oleh pemerintah sejalan dengan nawacita bertujuan untuk meningkatkan pemerataan taraf hidup dan kualitas hidup manusia, baik yang tinggal di perkotaan maupun di pedesaan.

Dalam Kurun waktu tahun 1990 hingga 2015, Indonesia memiliki gambaran perubahan tren perkembangan penyakit yang perlu mendapatkan perhatian khusus. Peningkatan persentase beban penyakit pada setiap dekade terlihat signifikan terutama Penyakit Tidak Menular (PTM) yang mengalami peningkatan hingga $12 \%$ setiap dekade, kecuali pada tahun 2015 mengalami penurunan sebesar $1 \%$. Sepuluh besar Penyakit yang merupakan penyebab kematian dan kecacatan adalah stroke, kecelakaan lalu lintas, jantung iskemik, kanker dan diabetes mellitus.

Pelayanan home care memiliki beberapa pengertian, diantaranya Perawatan di rumah yang merupakan lanjutan asuhan keperawatan dari rumah sakit yang sudah termasuk dalam rencana pemulangan (discharge planning), perawatan di rumah merupakan bagian dari asuhan keperawatan keluarga, sebagai tindak lanjut dari tindakan unit rawat jalan atau puskesmas. home care dapat diartikan juga pelayanan kesehatan berbasis perawatan dirumah yang memberika pelayanan keperawatan yang berkesinambungan dan komprehensif diberikan kepada individu dan keluarga di tempat tinggal mereka, yang bertujuan untuk meningkatkan, mempertahankan atau memulihkan kesehatan atau memaksimalkan tingkat kemandirian dan meminimalkan akibat dari penyakit termasuk penyakit terminal (Kementerian Kesehatan RI, 2019).

Perkesmas adalah pelayanan keperawatan profesional yang merupakan perpaduan antara konsep kesehatan masyarakat dan konsep keperawatan yang di tujukan pada seluruh masyarakat dengan penekanan pada keluarga resiko tinggi dalam upaya pencapaian derajat kesehatan yang optimal. Dilakukan melalui peningkatan kesehatan promotif dan preventif dengan menjamin keterjangkauan pelayanan kesehatan yang dibutuhkan dan melibatkan klien sebagai mitra kerja dalam perencanaan, pelaksanaan (Evaluasi Pelayanan Keperawatan).
Home Care telah diterapkan di berbagai Negara diantaranya: Indonesia berupa layanan pemberian obat, perawatan, rehabilitasi, dll (Udo Richter, Anika Reichert, Dominika Urbanski, Stefanie Scholz, 2014b), di Jerman layanan home care difokuskan pada upaya membimbing pasien untuk membantu diri sendiri dan merawatnya terus menerus. (Udo Richter, Anika Reichert, Dominika Urbanski, Stefanie Scholz, 2014a), di Inggris dikembangkan home care berbasis Sensor dengan memanfaatkan Bluetooth Low-Energy Beacons (BLE) (Power, Jackson, \& Dunnett, 2018).

Banyak program kesehatan yang telah dicanangkan oleh pemerintah untuk mewujudkan masyarakat sehat yang mandiri dan berkeadilan diantaranya program perkesmas dan Program Indonesia Sehat dengan pendekatan keluarga. Prinsipnya program ini memiliki tujuan yang sama yaitu masyarakat sehat yang mandiri melalui pendekatan keluarga. Yang dimaksud satu keluarga adalah satu kesatuan keluarga inti (ayah, ibu, dan anak) sebagaimana dinyatakan dalam Kartu Keluarga. Jika dalam satu rumah tangga terdapat kakek dan atau nenek atau individu lain, maka rumah tangga tersebut dianggap terdiri lebih dari satu keluarga. Untuk menyatakan bahwa suatu keluarga sehat atau tidak digunakan sejumlah penanda atau indikator.

Dalam rangka pelaksanaaan Program Indonesia Sehat telah disepakati adanya 12 indikator utama untuk penanda status kesehatan sebuah keluarga. Kedua belas indikator utama tersebut adalah sebagai berikut: (1) keluarga mengikuti program Keluarga Berencana (KB), (2) ibu melakukan persalinan di fasilitas kesehatan, (3) bayi mendapat imunisasi dasar lengkap, (4) bayi mendapat air susu ibu (ASI) eksklusif, (5) balita mendapatkan pemantauan pertumbuhan, (6) penderita tuberkulosis paru mendapatkan pengobatan sesuai standar, (7) penderita hipertensi melakukan pengobatan secara teratur, (8) penderita gangguan jiwa mendapatkan pengobatan dan tidak ditelantarkan, (9) anggota keluarga tidak ada yang merokok. (10) keluarga sudah menjadi anggota Jaminan Kesehatan Nasional (JKN), (11) keluarga mempunyai akses sarana air bersih, dan (12) keluarga mempunyai akses atau menggunakan jamban sehat (Kementerian Kesehatan RI, 2017).

Kementerian kesehatan telah membuat suatu aplikasi keluarga sehat, dimana aplikasi tersebut melaksanakan kegiatan sebagai berikut : Melakukan pendataan kesehatan keluarga menggunakan Prokesga oleh Pembina Keluarga (dapat dibantu oleh kader kesehatan), membuat 
dan mengelola pangkalan data Puskesmas oleh tenaga pengelola data Puskesmas, menganalisis, merumuskan intervensi masalah kesehatan, dan menyusun rencana Puskesmas oleh Pimpinan Puskesmas, melaksanakan penyuluhan kesehatan melalui kunjungan rumah oleh Pembina Keluarga, melaksanakan pelayanan profesional (dalam gedung dan luar gedung) oleh tenaga teknis/profesional Puskesmas dan melaksanakan Sistem Informasi dan Pelaporan Puskesmas oleh tenaga pengelola data Puskesmas (Kementerian Kesehatan RI, 2017).

Pada kenyataannya pada saat ini di Kabupaten Lampung Utara capaian program PISPK berupa hasil kunjungan keluarga dan intervensi awal baru mencapai $62,72 \%$ dari (data Dinkes Lampung Utara per Agustus 2019). Untuk mewujudkan 12 indikator Program Indonesia Sehat tersebut, dilakukan penghitungan Indeks Keluarga Sehat (IKS) dari setiap keluarga. Dalam pelaksanaan pendekatan keluarga ini tiga hal berikut harus diadakan atau dikembangkan, yaitu: Instrumen yang digunakan di tingkat keluarga, Forum komunikasi yang dikembangkan untuk kontak dengan keluarga dan Keterlibatan tenaga dari masyarakat sebagai mitra Puskesmas.

Keberhasilan Program Indonesia Sehat dengan Pendekatan Keluarga diukur dengan
Indeks Keluarga Sehat, yang merupakan komposit dari 12 indikator, yaitu: keluarga mengikuti program Keluarga Berencana (KB), Ibu melakukan persalinan di fasilitas kesehatan, Bayi mendapat imunisasi dasar lengkap, Bayi mendapat air susu ibu (ASI) eksklusif, Balita mendapatkan pemantauan pertumbuhan, Penderita tuberkulosis paru mendapatkan pengobatan sesuai standar, Penderita hipertensi melakukan pengobatan secara teratur, Penderita gangguan jiwa mendapatkan pengobatan dan tidak ditelantarkan, Anggota keluarga tidak ada yang merokok, Keluarga sudah menjadi anggota Jaminan Kesehatan Nasional (JKN), Keluarga mempunyai akses sarana air bersih, dan Keluarga mempunyai akses atau menggunakan jamban sehat. Semakin banyak indikator yang dapat dipenuhi oleh suatu keluarga, maka status keluarga tersebut akan mengarah kepada Keluarga Sehat. Sementara itu, semakin banyak keluarga yang mencapai status Keluarga Sehat, maka akan semakin dekat tercapainya Indonesia Sehat.

Program PIS-PK di Lampung Utara telah dilaksanakan pada semua Puskesmas, pendataan awal pada tahun 2018 didapatkan data kesehatan sebagai berikut:

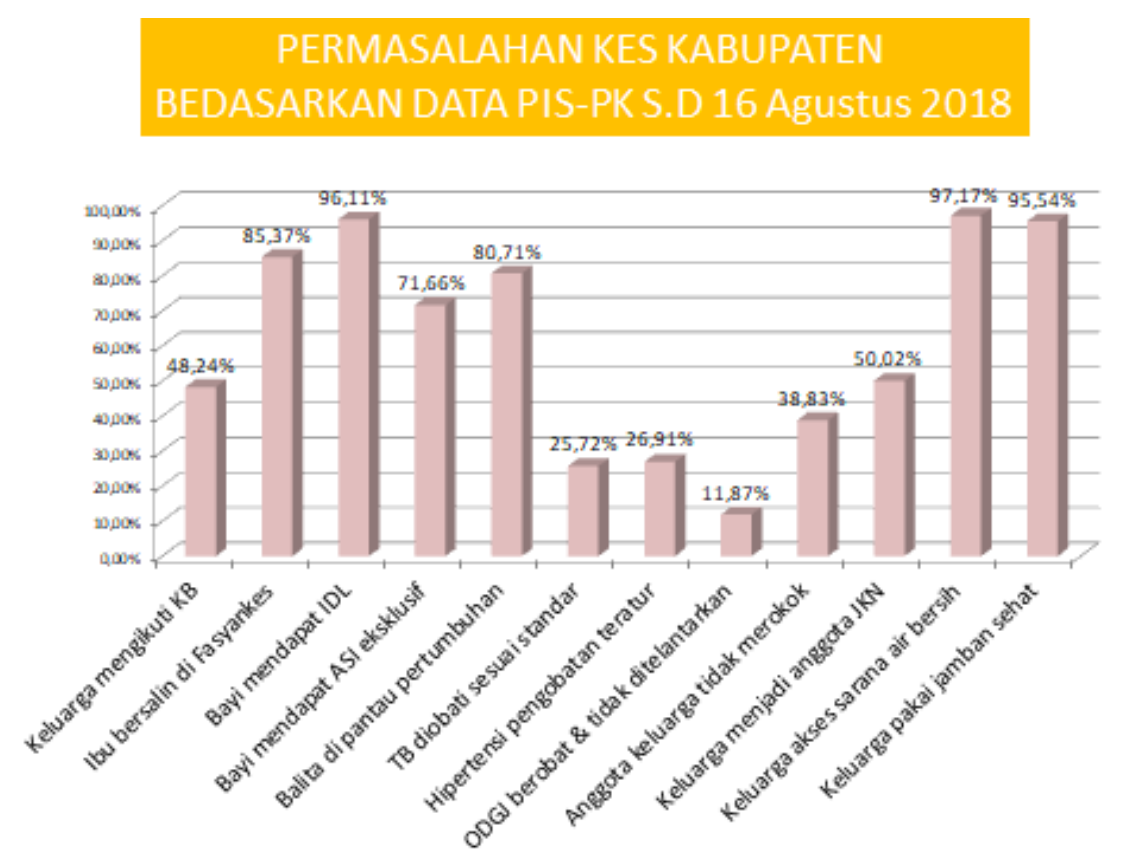

Gambar 1. Permasalahan Kesehatan Kabupaten Lampung Utara Berdasarkan Data PIS-PK (Kementerian Kesehatan RI, 2017)

Dari Gambar 1 dapat dilihat beberapa permasalahan kesehatan yang perlu ditindaklanjuti di Lampung Utara yaitu: bahwa gangguan jiwa berat diobati dan tidak ditelantarkan (11,87\%), penderita TB Paru berobat sesuai standar $(25,72 \%)$, penderita hipertensi yang berobat teratur $(26,91 \%)$, anggota keluarga tidak ada yang merokok $(38,83 \%)$, keluarga mengikuti program KB $(48,24 \%)$, keluarga sudah menjadi anggota JKN $(50,02 \%)$. Untuk mengatasi permasalahan kesehatan keluarga tersebut, perlu ditindaklanjuti dengan 
intervensi, untuk itu dengan keterbatasan tenaga, jauhnya jarak tempuh/luasnya lokasi, keterbatasan waktu, dibutuhkan teknologi untuk dapat melengkapi keterbatasan tersebut, diantaranya dengan teknologi Telehealth.

Indonesia saat ini memasuki era teknologi 4.0 dan diperkirakan memiliki jumlah penduduk 250 juta jiwa yang merupakan suatu bonus demografi dimana usia produktif berkisar Antara 18 tahun hingga 55 tahun, dan hal ini merupakan sasaran dari PTM diakibatkan oleh gaya hidup dan faktor lainnya oleh sebab itu diperlukan pengawasan dan pengendalian kesehatan yang memadai diantaranya melalui teknik Telehealth yang relevan untuk digunakan di Indonesia, beberapa tempat telah memanfaatkan penerapan Telehealth untuk perawatan Homecare (Istifada, Sukihananto, \& Laagu, 2017).

Teknologi Telehealth dapat memudahkan tenaga kesehatan dalam memberikan upaya promotif, preventif maupun kuratif yang digunakan oleh dokter, perawat atau tenaga kesehatan lain (McManus RJ, Mant J, Bray EP, Holder R, Jones MI, Greenfield S, Kaambwa B, Banting M, Bryan S, Little P, Williams B, 2010). Diharapkan Pasien dengan Telehealth akan menunjukkan kecenderungan umum yang dapat mempengaruhi layanan kesehatan terkait informasi melalui media telekomunikasi. Dengan Telehealth pemberi layanan kesehatan dapat lebih efektif melakukan monitoring pasien jarak jauh seperti memonitor tanda-tanda vital pasien, berat badan, tekanan darah, nadi dan indikasi penting lainnya. Sejatinya teknologi Telehealth ini memberikan banyak manfaat dan solusi dalam pengendalian Penyakit Tidak Menular untuk itu dibutuhkan suatu kajian lebih mendalam terhadap teknologi ini (Cottrell, Cox, O'Connell, \& Chambers, 2015).

Telehealth adalah informatika keperawatan mengintegrasikan ilmu keperawatan, komputer, ilmu pengetahuan, dan ilmu informasi untuk mengelola dan mengkomunikasikan data, informasi, dan pengetahuan dalam praktek keperawatan. Informatika keperawatan memfasilitasi integrasi data, informasi, dan pengetahuan untuk dukungan klien, perawat, dan penyedia lainnya dalam pengambilan keputusan mereka dalam semua peran dan pengaturan.

Penelitian Telehealth telah banyak dilakukan dalam layanan kesehatan, diantaranya penelitian Jonsson and Willman menemukan bahwa telenursing dengan menggunakan teknologi audio-vidio sangat efektif untuk melakukan komunikasi antara perawat dan pasien dan memberikan kepuasan pada perawat dan klien dalam melakukan perawatan rumah
(Jönsson \& Willman, 2008), teknologi telenursing dapat membantu pasien untuk mandiri merawat dirinya (Hartford, 2005), telenursing dapat pelayanan keperawatan lebih mudah diakses (Bohnenkamp, Mcdonald, Lopez, Krupinski, \& Blackett, 2004).

Pada penelitian ini adalah memadukan antara telenursing dengan program pemerintah PIS-PK (Program Indonesia Sehat dengan Pendekatan Keluarga), yang selama ini baru dilakukan pendataan saja, belum dilakukan tindak lanjut pada tindakan pemecahan masalah.

Tujuan Penelitian ini adalah mendesain Model SIPISPeKa dalam intervensi program Indonesia Sehat dengan Pendekatan Keluarga (PIS-PK), menilai fungsionalitas SIPISPeKa sebagai layanan kesehatan Program PIS-PK dan menentukan kelayakan SIPISPeKa sebagai media layanan kesehatan Program PIS-PK .

\section{METODE}

Desain penelitian ini adalah pengembangan prototype SIMPISPeKa yang sesuai dengan kebutuhan Puskesmas dalam memberikan pelayanan kesehatan bagi keluarga dalam kategori Keluarga bermasalah dalam penilaian PIS-PK.

Populasi dalam penelitian ini adalah seluruh Keluarga di Kelurahan Tanjung Aman, Pemilihan sampel dengan menggunakan metode purposive sampling, dengan kriteria inklusi sampel sebagai berikut: 1) Keluarga dengan kategori Keluarga Tidak Sehat, 2) Bersedia menjadi responden, 3) memiliki alat komunikasi android dan mampu mengoperasikannya. Namun pada saat pelaksanaan, beberapa Kepala keluarga tidak mampu mengoperasikan android sehingga untuk memenuhi jumlah sampel KK yang diambil sebagai sampel adalah tidak hanya Keluarga yang dalam ketegori Tidak Sehat. Jumlah sampel dalam penelitian ini adalah 147 orang.

Penelitian ini telah mendapatkan persetujuan etik dari Komisi Etik Penelitian Kesehatan Politeknik Kesehatan Tanjung Karang. Penelitian ini dilakukan di Kelurahan Tanjung Aman Kecamatan Kotabumi Selatan Kabupaten Lampung Utara, Penelitian dilaksanakan selama bulan Maret sampai dengan Nopember 2020. Data yang diperoleh melalui angket yang terkumpul selanjutnya dianalisis dengan statistik kuantitatif. Hasil angket dianalisis menggunakan kriteria sebagai berikut (Mardapi, 2008 dalam (Astuti, et al., 2015). 
Tabel 1. Kategori Skala 4

\begin{tabular}{cl}
\hline Skor Nilai & \multicolumn{1}{c}{ Interpretasi } \\
\hline 4 & Sangat Layak \\
3 & Layak \\
2 & Tidak Layak \\
1 & Sangat Tidak layak \\
\hline
\end{tabular}

Skor yang diperoleh dikonversikan menjadi nilai pada skala 4 yang dijelaskan pada tabel 2.

Tabel 2. Kategori Penilaian

\begin{tabular}{ll}
\hline Interval Skor & Kategori \\
\hline $\mathrm{X}>\mathrm{M} i+1,5(\mathrm{SDi})$ & Sangat Layak \\
$\mathrm{M} i<\mathrm{X}<\mathrm{M} i+1,5(\mathrm{SDi})$ & Layak \\
$\mathrm{M} i-1,5(\mathrm{SDi})<\mathrm{X}<\mathrm{M} i$ & Tidak Layak \\
$\mathrm{X}<\mathrm{M} i-1,5(\mathrm{SDi})$ & Sangat Tidak layak \\
\hline
\end{tabular}

\section{HASIL}

\section{Prosedur Pengembangan Aplikasi SIPISPeKa}

Pengembangan aplikasi media pembelajaran mengoperasikan sistem pengendali elektronik yang dilakukan dalam penelitian ini menggunakan model pengembangan software oleh Pressman (1996) dengan model pengembangan waterfall yang terdiri dari 4 tahap kegiatan yaitu: (1) software requirement analysis (analisis kebutuhan perangkat lunak), (2) design (perancangan), (3) code generation (penulisan kode) dan (4) testing pengujian).

Pada tahap 1 analisis kebutuhan perangkat lunak, dilakukan melalui assessment lapangan dan FGD, antara pemegang program PIS-PK dengan ahli media, selanjutnya pada tahap 2 perancangan dilakukan dengan 2 tahap, yaitu pertama perancangan materi/susbtansi/isi dan kedua perancangan aplikasi. Tahap 3: penulisan kode dilakukan oleh ahli media dan selanjutnya tahap 4 dilakukan testing (pengujian) terhadap aplikasi SIPISPeKa, pengujian dilakukan oleh user, untuk selanjutnya dilakukan penilaian.
Rancangan Aplikasi SIPISPeKa, adalah sebagai berikut:

a. Pengguna aplikasi terdiri dari: super admin, pemegang program dan kepala keluarga, pengguna login dengan username dan password masing-masing.

b. Alur pesan yang disampaikan

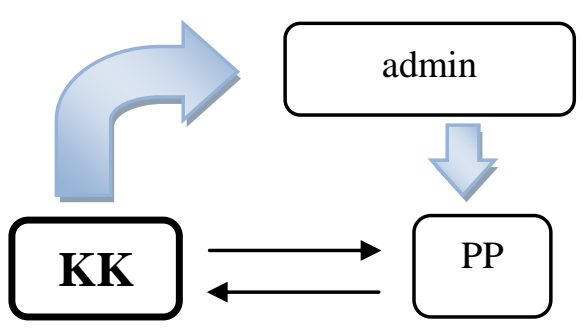

Gambar 2. Alur Komunikasi Aplikasi SIPISPeKa

Keterangan:

KK = Kepala Keluarga

PP = Pemegang Program

$\longrightarrow=$ KK menyampaikan keluhan/konsultasi

$\leftarrow$ = intervensi : konseling/homecare

c. Semua aktifitas/interaksi antara KK-PP terdokumentasi dan dapat di print-out untuk laporan.

Dengan tampilan sebagai berikut :

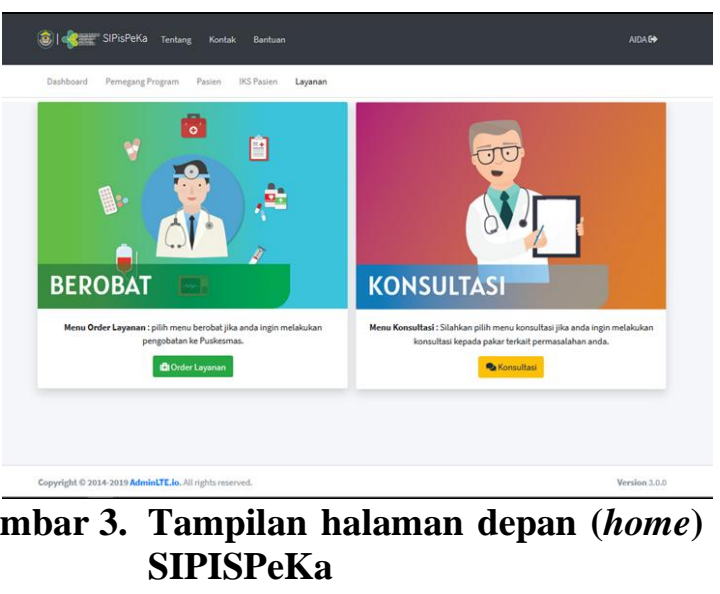

Gambar 3 menunjukkan tampilan depan Aplikasi SIPISPeKa, dimana ada 2 menu pilihan yaitu menu berobat dan konsultasi 


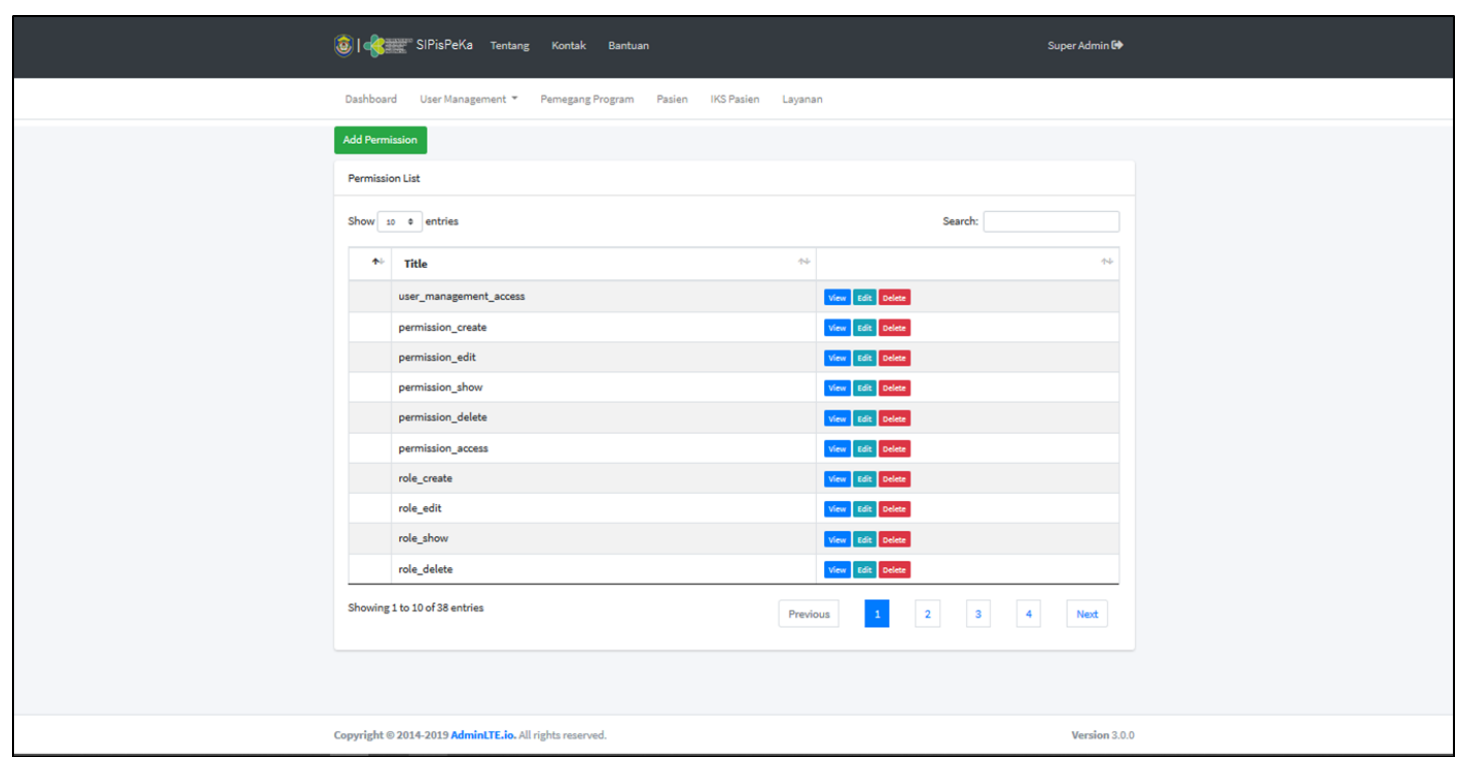

Gambar 4 : Menu User Management SIPISPeKa

Gambar 4 menunjukkan gambar tampilan menu User management. Tampilan aplikasi SIPISPeKa, terdapat 3 pilihan yaitu Permission, Roles dan Users. Users terdiri dari: admin, pemegang program, dan pasien (Kepala Keluarga).

\section{Analisis Data Fungsionalitas SIPISPeKa}

\section{Uji Validitas Ahli Media}

Data hasil uji validasi oleh ahli media berupa skor dikonversikan ke dalam nilai baku dengan rentang skor $0-100$. Penilaian oleh ahli media dinilai dari 32 butir indikator penilaian. 32 Butir penilaian tersebut terdiri dari 15 butir aspek kaidah media telehealth, 6 butir aspek tata laksana dan 11 butir aspek media media sistem informasi berbasis web, dengan hasil dapat dilihat pada tabel berikut:

Tabel 3. Hasil Penilaian Validator (Ahli Media) terhadap Aplikasi SIPISPeKa dari Aspek Kaidah Media Telehealth, Tata Laksana dan Media sistem Informasi Berbasis Web

\begin{tabular}{lrrrr}
\hline & $\begin{array}{c}\text { Kaidah Media } \\
\text { Telehealth }\end{array}$ & $\begin{array}{c}\text { Tata } \\
\text { Laksana }\end{array}$ & $\begin{array}{c}\text { Media Sistem Informasi } \\
\text { Berbasis Web }\end{array}$ & $\begin{array}{c}\text { Skor } \\
\text { Total }\end{array}$ \\
\hline Ahli Media 1 & 59 & 23 & 42 & 124 \\
Ahli Media 2 & 55 & 20 & 43 & 118 \\
Ahli Media 3 & 53 & 22 & 40 & 115 \\
Ahli Media 4 & 57 & 22 & 44 & 123 \\
Rerata Score & 56 & 21,75 & 42,25 & 120 \\
Mi $i$ (SDi) & 56 & 21,5 & 42 & 119,5 \\
1,5 (SDi) & 1,5 & 0,75 & 1 & 2,25 \\
Mi+1,5(SDi) & 57,5 & 22,25 & 43 & 121,75 \\
Mi-1,5(SDi) & 54,5 & 20,75 & 41 & 117,25 \\
Kategori & Layak & Layak & Layak & Layak \\
\hline
\end{tabular}

Dari Tabel 3 dapat dijelaskan rata-rata hasil penilaian oleh ahli media pada aspek kaidah media telehealth, aspek tata laksana dan aspek media sistem informasi berbasis web masuk dalam kategori Layak. 


\section{Uji Validitas Ahli Materi (PIS-PK)}

Tabel 4. Hasil Penilaian Validator (Ahli Materi) terhadap Aplikasi SIPISPeKa dari aspek Kaidah Media Telehealth, Tata Laksana dan Relevansi

\begin{tabular}{lrrrr}
\hline & $\begin{array}{c}\text { Kaidah Media } \\
\text { Telehealth }\end{array}$ & $\begin{array}{c}\text { Tata } \\
\text { Laksana }\end{array}$ & Relevansi & Skor Total \\
\hline Ahli Materi 1 & 60 & 24 & 64 & 148 \\
Ahli Materi 2 & 52 & 19 & 62 & 133 \\
Rerata Score & 56 & 21,5 & 63 & 140,5 \\
Mi & 56 & 21,5 & 63 & 140,5 \\
$1,5($ SDi) & 2 & 1,25 & 0,49 & 3,75 \\
Mi+1,5(SDi) & 58 & 22,75 & 63,49 & 144,25 \\
Mi-1,5(SDi) & 54 & 20,25 & 62,51 & 136,75 \\
Kategori & Layak & Layak & Layak & Layak \\
\hline
\end{tabular}

Dari Tabel 4 dapat dijelaskan rata-rata hasil penilaian oleh ahli materi pada aspek kaidah media telehealth, aspek tata laksana dan aspek relevansi dengan PIS-PK masuk dalam kategori Layak dimana nilai $\mathrm{M} i<\mathrm{X}<\mathrm{M} i+1,5(\mathrm{SDi})$, walaupun cendrung kurang layak, karena nilai rerata $\operatorname{Score}(\mathrm{X})=\mathrm{Mi}$.

\section{Hasil Uji Pengguna Pertama (Petugas Puskesmas)}

Setelah dilakukan validasi dan dinyatakan layak untuk digunakan kemudian dilakukan uji pengguna pertama oleh petugas Puskesmas. Data hasil uji pengguna pertama oleh petugas Puskesmas berupa skor dikonversikan ke dalam nilai baku dengan rentang skor 0-100. Penilaian oleh petugas Puskesmas dinilai dari 47 butir indikator penilaian. 47 butir penilaian tersebut terdiri dari 15 butir aspek kaidah media telehealth, 6 butir aspek tata laksana, 11 butir aspek media sistem informasi berbasis web dan 15 butir aspek relevansi dengan Program PIS-PK. Berikut kategori penilaian yang telah dikonversikan ke dalam nilai baku.

Tabel 5. Hasil Penilaian Pengguna (Petugas Kesehatan) terhadap Aplikasi SIPISPeKa dari Aspek Kaidah Media Telehealth, Tata Laksana Media Sistem Informasi Berbasis Web dan Aspek Relevansi

\begin{tabular}{lrrrrr}
\hline & $\begin{array}{c}\text { Kaidah Media } \\
\text { Telehealth }\end{array}$ & $\begin{array}{c}\text { Tata } \\
\text { Laksana }\end{array}$ & $\begin{array}{c}\text { Media Sistem Informasi } \\
\text { Berbasis Web }\end{array}$ & $\begin{array}{c}\text { Relevansi } \\
\text { Skor } \\
\text { Total }\end{array}$ \\
\hline Admin & 50 & 20 & 35 & 45 & 150 \\
PP 1 & 46 & 18 & 35 & 59 & 158 \\
PP 2 & 42 & 14 & 29 & 45 & 130 \\
PP 3 & 44 & 18 & 31 & 44 & 137 \\
PP 4 & 43 & 15 & 26 & 45 & 129 \\
PP 5 & 44 & 16 & 26 & 45 & 131 \\
PP 6 & 41 & 16 & 28 & 44 & 129 \\
PP 7 & 53 & 19 & 39 & 58 & 169 \\
Rerata Score (X) & 45,4 & 17 & 31,1 & 48,1 & 141,6 \\
Mi & 45,5 & 17 & 32,5 & 51,5 & 149 \\
1,5 (SDi) & 3 & 1,25 & 3,25 & 3,75 & 10 \\
Mi+1,5 (SDi) & 48,5 & 18,25 & 35,75 & 55,25 & 159 \\
Mi-1,5(SDi) & 42,5 & 15,75 & 29,25 & 47,75 & 139 \\
Kategori & Layak & Layak & Layak & Layak & Layak \\
\hline
\end{tabular}

Dari Tabel 5 rata-rata hasil penilaian oleh petugas Puskesmas pada aspek kaidah media telehealth, masuk dalam kategori layak $(\mathrm{M} i<\mathrm{X}<\mathrm{M} i+1,5(\mathrm{SDi}))$, aspek tata laksana masuk dalam kategori layak walaupun cenderung tidak layak $(\mathrm{X}=\mathrm{M} i)$, aspek media sistem informasi berbasis web dalam kategori tidak layak $(\mathrm{X}<\mathrm{Mi})$ dan aspek relevansi dengan PIS-PK masuk dalam kategori Tidak Layak $(\mathrm{X}<\mathrm{M} 1)$.
Data hasil uji beta oleh siswa berupa skor dikonversikan ke dalam nilai baku dengan rentang skor 0-100. Penilaian oleh kepala keluarga dinilai dari 47 butir indikator penilaian. 41 Butir penilaian tersebut terdiri dari 15 butir aspek kaidah media telehealth, 11 butir aspek media sistem informasi berbasis web dan 15 butir aspek relevansi dengan Program PIS-PK. 
Tabel 6. Hasil Penilaian Pengguna (Kepala Keluarga) terhadap Aplikasi SIPISPeKa dari Aspek Kaidah Media Telehealth, Media sistem Informasi Berbasis Web dan Aspek Relevansi

\begin{tabular}{lrrrr}
\hline & $\begin{array}{c}\text { Kaidah Media } \\
\text { Telehealth }\end{array}$ & $\begin{array}{c}\text { Media Sistem Informasi } \\
\text { Berbasis Web }\end{array}$ & Relevansi & $\begin{array}{c}\text { Skor } \\
\text { Total }\end{array}$ \\
\hline Rerata Score (X) & 47,7 & 34,8 & 46,6 & 129,2 \\
Mi & 45 & 34 & 45,5 & 124,5 \\
1,5 (SDi) & 3,5 & 4 & 7,25 & 14,75 \\
Mi+1,5(SDi) & 48,5 & 38 & 52,75 & 139,25 \\
Mi-1,5(SDi) & 41,5 & 30 & 38,25 & 109,75 \\
Kategori & Layak & Layak & Layak & Layak \\
\hline
\end{tabular}

Dari Tabel 6 rata-rata hasil penilaian oleh Kepala Keluarga pada aspek kaidah media telehealth, aspek media sistem informasi berbasis web dan aspek relevansi dengan PIS-PK masuk

dalam kategori Layak, karena nilai masingmasing komponen penilaian berada diantara nilai Mi dengan Mi+1,5(SDi), $(\mathrm{M} i<\mathrm{X}<\mathrm{M} i+1,5(\mathrm{SDi}))$.

Tabel 7. Komentar Saran Validator dan Pengguna terhadap Aplikasi SIPISPeKa.

\begin{tabular}{|c|c|}
\hline No & Komentar/Saran \\
\hline 1. & Lebih aplicable bukan hanya versi web, tapi android. \\
\hline 2. & $\begin{array}{l}\text { Ada menu pembatalan layanan, karena sesuatu hal misal berobat tenpat lain, atau belum } \\
\text { dilayani sudah sembuh dan lainnya. }\end{array}$ \\
\hline 3. & $\begin{array}{l}\text { Ada alert yang signifikan ketika ada permintaan layanan masuk, sehingga respon time tindak } \\
\text { lanjut lebih cepat. }\end{array}$ \\
\hline 4. & $\begin{array}{l}\text { Ada notifikasi jika ada pesan dari admin ke hp pasien atau pengguna, sehingga lebih cepat } \\
\text { dibaca. }\end{array}$ \\
\hline 5. & $\begin{array}{l}\text { Dapat di integrasikan ke aplikasi PIS-PK Kemenkes dan Sistem Informasi Puskesmas (SIP), } \\
\text { sehingga petugas merasa terbantu dan bukan membebani, karema banyaknya aplikasi yang } \\
\text { tidak saling terintegrasi. }\end{array}$ \\
\hline 6. & $\begin{array}{l}\text { Sebaiknya merealisasikan tujuan kebijakan melalui komitmen dinas kesehatan maupun } \\
\text { instansi yang melibatkan berbagai puskesmas Pada kabupaten yang belum melibatkan peran } \\
\text { serta dinas kesehatan maupun melaksanakan pendataan dan perlu ditingkatkan kembali } \\
\text { puskesmas dan lintas sektor terkait. }\end{array}$ \\
\hline 7. & $\begin{array}{l}\text { Aplikasi SIPISPeka agar dapat menjadi aplikasi untuk mempermudah dalam intervensi lanjut } \\
\text { dari } 12 \text { indikator kesehatan keluarga. }\end{array}$ \\
\hline 8. & $\begin{array}{l}\text { Tujuan dari aplikasi SIPISPeka itu untuk efisiensi tenaga dan waktu. Format aplikasi } \\
\text { SIPISPeKa ini dibuat untuk mempermudah aplikasi dari PISPK Pusdatin (Kementerian RI) } \\
\text { seperti pada aplikasi PISPK (Kementerian RI) ini baik data offline maupun online cukup } \\
\text { dengan satu kali entry. }\end{array}$ \\
\hline 9. & Aplikasi SIPISPeka agar dapat membantu pelaksanaan PIS-PK di wilayah Puskesmas. \\
\hline 10. & $\begin{array}{l}\text { Pendataan yang valid menjadi sangat penting karena output yang dihasilkan akan dijadikan } \\
\text { sebagai informasi untuk membuat perencanaan puskesmas. }\end{array}$ \\
\hline
\end{tabular}

\section{PEMBAHASAN}

\section{Kaidah Media Telehealth}

Pengembangan telehealth dalam bentuk aplikasi SIPISPeKa, merupakan salah satu pengembangan model teknologi Telehealth (juga dikenal sebagai telemedicine kedokteran digital) adalah konsep alternatif layanan baru dalam penyediaan layanan kesehatan, yang dianggap sebagai mode yang berguna untuk mengelola pasien di lokasi terpencil (Binks \& Benger, 2007)

Hasil penelitian penilaian user (petugas Puskesmas dan masyarakat) menunjukkan bahwa SIMPISPeKa dalam kategori layak dilihat dari kaidah media telehealth, tata laksana, media sistem informasi berbasis web dan relevansi dengan PIS-PK.
Penilaian dari sudut pandang kaidah media telehealth dengan indikator penilaian apakah SIPISPeKa telah memenuhi kaidah sebagai media telehealth, hasil penelitian menunjukkan bahwa dalam ketegori layak, namun masih perlu banyak perbaikan, perbaikan yang dimaksud diantaranya adalah: perlu penambahan fitur-fitur agar mudah untuk dioperasikan.

Telah banyak penggunaan telehealth di layanan kesehatan, dengan berbagai nama seperti telenursing, telemedicine ataupun telehealth, namun semuanya prinsipnya sama yaitu memanfaatkan teknologi informatika untuk mempermudah layanan kesehatan, spesifiknya keperawatan dan kedokteran, beberapa penelitian di bidang keperawatan tentang penggunaan Aplikasi telenursing antara lain: penelitian Jerant, et al (2003) membandingkan 3 perawatan 
modalitas untuk menurunkan kekambuhan CHF selama 180 hari follow up. Subjek menerima kunjungan dasar selama 60 hari dan mendapat satu dari 3 terapi modalitas: (a) video-based home telecare; (b) telephone calls; and (c) usual care Kekambuhan pada CHF menurun lebih dari $80 \%$ dengan telenursing dibandingkan dengan perawatan biasa. Dari penelitian ini juga menurunkan kunjungan emergensi pada CHF. Pada perawatan diri kedua grup tidak ada perbedaan secara signifikan tentang kepatuhan, pengobatan, status kesehatan dan kepuasan. Telenursing dapat menurunkan hospitalisasi pada CHF dan meningkatkan frekuensi komunikasi dengan pasien (Mcwilliam, et al., 2008).

Penelitian Ameen, Coll, \& Peters, menunjukkan hasil bahwa terdapat perbaikan yang signifikan dalam hal kemampuan perawat komunitas dalam manajemen perawatan ulkus kaki antara sebelum dan sesudah intervensi melalui telenursing. Hasil penelitian menunjukkan bahwa tele-saran dapat menjadinmanfaat besar bagi perawat komunitas dalam meningkatkan pengetahuan mereka dalam praktek perawatan ulkus kaki. Ini akan memiliki implikasi signifikan untuk penggunaan sumber daya manusia yang lebih efisien dan efektivitas biaya dalam perawatan luka (Ameen, Coll, \& Peters, 2005).

Muzammil, dalam penelitiannya menjelaskan bahwa Telehealth dianggap sebagai modalitas penyediaan kesehatan untuk daerah pedesaan dan terpencil, tetapi hal ini berubah, terutama karena sumber daya yang terbatas dan harapan pasien yang meningkat. Ini muncul sebagai alat yang berharga untuk semua tingkat perawatan kesehatan. Pemerintah negara berpenghasilan rendah cenderung menghabiskan lebih sedikit untuk perawatan kesehatan, dan karena telehealth adalah konsep yang relatif lebih baru, pendanaan yang dialokasikan bahkan lebih sedikit (Muzammil, 2020).

Ciri-ciri telehealth adalah : interaktif, membutuhkan biaya telekomunikasi dan teknologi, transmisi multimedia, response time, menyediakan layanan data pasien, konsultasi, pelayanan keperawatan primer, menurunkan biaya tatap muka (Muzammil, 2020).

Hal yang diharapkan dengan penggunaan telehealth adalah mengurangi waktu tunggu dan mengurangi kunjungan yang tidak perlu, mempersingkat hari perawatan dan mengurangi biaya perawatan, membantu memenuhi kebutuhan kesehatan, memudahkan akses petugas kesehatan yang berada di daerah yang terisolasi, berguna dalam kasus-kasus kronis atau kasus geriatik yang perlu perawatan di rumah dengan jarak yang jauh dari pelayanan kesehatan, mendorong tenaga kesehatan atau daerah yang kurang terlayani untuk mengakses penyedia layanan melalui mekanisme seperti konferensi video dan internet (Gott, 1995).

\section{Tata Kelola SIPISPeKa}

Penilaian Tata kelola SIPISPeKa, dinilai dari apakah Aplikasi Sipispeka memenuhi sasaran sebagai media promosi kesehatan, apakah dapat dipahami keluarga/sasaran layanan kesehatan, bagaimana penyampaian Informasi yang ditampilkan, bagaimana penerimaan Informasi pada masyarakat, apakah dapat menggantikan layanan kesehatan dengan cara bertemu langsung, dan bagaimana menu layanan yang ditampilkan.

Didapatkan hasil dari penilaian tata kelola bahwa Aplikasi SIPISPeKa, dalam kategori layak, beberapa komentar dan saran ahli materi (SIPISPeKa) diantaranya dan user menyatakan bahwa aplikasi ini sangat membantu, walaupun tidak sedikit yang memberikan komentar bahwa aplikasi ini masih membingungkan dalam mengoperasionalkannya, dan menu layanan yang diberikan belum tergambar dengan jelas. Penelitian terkini menunjukkan bukti efektivitas dan penerimaan telemedicine. Telekonsultasi di reumatologi layak dan dapat diterima. Mereka menemukan bahwa pasien puas dengan metode telehealth, dan $84 \%$ merasa bahwa perawatan yang diterima sebaik kunjungan "secara langsung". Studi mereka memang bergantung pada keterampilan keluarga dalam mengoperasikan telehealth (West, 2020), (McSwain. et al, 2019). Penelitian Muzammil (2020) menyatakan ada beberapa faktor yang perlu dipertimbangkan dalam pengembangan telehealth. Pasien didaerah perkotaan mungkin memiliki pandangan yang berbeda dengan mereka yang tinggal di daerah terpencil dan pedesaan, namun pada semua kasus, pasien lebih nyaman menemui penyedia layanan kesehatan langsung. Namun telehealth dapat menjadi solusi bagi layanan kesehatan di pedesaan, dimana masyarakat kurang mendapatkan akses layanan kesehatan yang memedai, dokter spesialis yang kurang, dan infrastruktur yang tidak sesuai, dan jarak yang jauh harus ditempuh untuk menerima perawatan (Muzammil, 2020).

\section{Media Sistem Informasi Berbasis Web}


Beberapa komentar dan saran yang disampaikan responden, terkait media sistem informasi berbasis web ini adalah, beberapa responden menyatakan aplikasi ini tidak praktis karena harus membuka dari browser, yang diharapkan adalah aplikasi ini dapat diunduh dengan pilihan menu yang telah tersedia sehingga mengoperasikannya menjadi lebih praktis. Hal ini tidak sejalan dengan penelitian Sensuse dan Prayoga (2012) menyatakan bahwa kemudahan menggunakan aplikasi (Ease of Use), kecepatan akses data dan pemrosesan pada aplikasi (Download Delay), tampilan Informasi secara khusus untuk setiap tidak memiliki pengaruh positif secara langsung terhadap kepuasan (UserSatisfaction) pengunjung website aplikasi. (Sensuse \& Prayoga, 2012).

Beberapa negara telah menerapkan telehealth pada layanan yang diberikan, di Amerika layanan berupa layanan spesialis (Muzammil, 2020), di India menyediakan perawatan gawat darurat dengan aplikasi System Telehealth Emergency (Ade, Doulamis, Wagle, \& Ullah, 2011), namun sebagain besar aplikasi telehealth yang dikembangkan adalah berupa pesanan layanan kepada dokter, tentang keluhan penyakit yang dialami user, diantaranya yang berkembang saat ini aplikasi Halodoc (https://www.halodoc.com), Alodokter (https://www.alodokter.com/). Aplikasi ini menyediakan layanan konsultasi, promosi kesehatan, sampai dengan dokter meresepkan obat, dan lain-lain

Media sistem informasi telah banyak dikembangkan di Indonesia, beberapa prototype bahkan media telah digunakan di berbagai bidang layanan, diantaranya sebagai media pembelajaran, terutama saat ini dengan Pandemi Covid-19, media informatika sangat dibutuhkan, penelitian Nugroho dan Saleh menemukan bahwa Sebanyak $96 \%$ menyatakan program pembelajaran berbasis web sangat menarik dan sangat membantu dalam kegiatan pembelajaran. Selain itu $90 \%$ menyatakan program ini dapat mengatasi kebosanan terhadap perkuliahan di kelas dalam bentuk metode ceramah (Nugroho \& Saleh, 2012), sebagai media pelatihan, Napitupulu mengembangkan sistem informasi berbasis web untuk pelatihan, didapatkan hasil bahwa sistem informasi pelatihan berbasis web yang dirancang dapat memberikan informasi menyeluruh mengenai jasa pelatihan yang ditawarkan, lebih efisien dan efektif serta dapat digunakan untuk pendokumentasian paperless (Napitupulu, 2006).

Beberapa pengembangan media sistem informasi berbasis web yang lain diantaranya
Rancang Bangun Sistem Informasi Holtikultural (Susanto, et al., 2020), Pengembangan Sistem Informasi Upt Kalibrasi (Firdaus, Pramono, \& Purnomo, 2020).

Pengembangan media sistem informasi berbasis web pada layanan kesehatan juga telah banyak dikembangkan diantaranya Sistem Informasi Pelayanan Puskesmas Tanjung Medan Kab. Labuhan Batu Selatan Berbasis Web (Munandar \& Masrizal, 2020), Sistem Informasi Rekam Medis Pasien Rawat Jalan di UPTD Puskesmas Kuningan Berbasis Web (Saputra, Tatang; Kurniadi, 2019) dan Sistem Informasi Layanan Puskesmas Berbasis Web (Putri \& Kurniasari, 2020).

Pengembangan sistem informasi berbasis web yang telah banyak dikembangkan di luar negeri maupun di dalam negeri pada prinsipnya sama yaitu mengembangan sistem informasi yang mempermudah akses layanan, mempermudah komunikasi antara pemberi dan penerima layanan mempersingkat waktu dan jarak (Bauer, 2001). Namun pengembangan SIPISPeKa adalah sistem informasi yang merupakan media terlaksananya program Kesehatan Nasional : Program Indonesia Sehat berbasis Pendekatan Keluarga, terutama pada tindak lanjut intervensi terhadap pendataan yang telah dilaksanakan terintegrasi secara Nasional (Kementerian Kesehatan, 2018).

\section{Relevansi SIPISPeKa dengan PIS-PK}

Hasil penilaian responden terhadap SIPISPeKa dilihat dari relevansinya dengan program PIS-PK, menunjukkan bahwa SIPISPeKa dalam kategori Layak, penilaian ini dilihat dari 12 program PIS-PK. Program Indonesia Sehat merupakan salah satu program dari agenda ke-5 Nawa Cita, yaitu meningkatkan kualitas hidup manusia Indonesia. Program ini didukung oleh program sektoral lainnya yaitu Program Indonesia Pintar, Program Indonesia Kerja, dan Program Indonesia Sejahtera. Program Indonesia Sehat selanjutnya menjadi program utama Pembangunan Kesehatan yang kemudian direncanakan pencapaiannya melalui Rencana Strategis Kementerian Kesehatan Tahun 20152019, yang ditetapkan melalui Keputusan Menteri Kesehatan R.I. Nomor HK.02.02/Menkes/52/2015.

Dalam rangka pelaksanaaan Program Indonesia Sehat telah disepakati adanya 12 indikator utama untuk penanda status kesehatan sebuah keluarga. Kedua belas indikator utama tersebut adalah: (1) Keluarga mengikuti program Keluarga Berencana (KB), (2) Ibu melakukan persalinan di fasilitas kesehatan, (3) Bayi 
mendapat imunisasi dasar lengkap, (4) Bayi mendapat air susu ibu (ASI) eksklusif, (5) Balita mendapatkan pemantauan pertumbuhan, (6) Penderita tuberkulosis paru mendapatkan pengobatan sesuai standar, (7) Penderita hipertensi melakukan pengobatan secara teratur, (8) Penderita gangguan jiwa mendapatkan pengobatan dan tidak ditelantarkan, (9) Anggota keluarga tidak ada yang merokok, (10) Keluarga sudah menjadi anggota Jaminan Kesehatan Nasional (JKN), (11) Keluarga mempunyai akses sarana air bersih, dan (12) Keluarga mempunyai akses atau menggunakan jamban sehat.

Penelitian yang dilakukan oleh Afrianti (2020) yang melakukan studi literatur terhadap 186 penelitian PIS-PK, hasil tinjauan tersebut didapat hasil bahwa kendala pada pelaksanaan PIS-PK adalah pada Petugas PIS-PK, penginputan data, fasilitas dan infrastruktur, pencairan dana, dan kekurangan kerjasama lintas sektoral (Afrianti, 2020). Penelitian yang dilakukan oleh Putra dan Hasanah tentang sikap masyarakat terhadap program PIS-PK, hasilnya menunjukkan bahwa 66\% keluarga bersikap positif terdahap program ini (Putra \& Hasana, 2020).

Komentar dan saran oleh ahli materi (PISPK) dan admin dan pemegang program terhadap SIPISPeKa diantaranya adalah bahwa program ini dibutuhkan untuk pengembangan Program Indonesia Sehat dengan Pendekatan Keluarga (PIS-PK) dengan perbaikan berupa penambahan beberapa pilihan menu yang disesuaikan dengan 12 indikator PIS-PK, dapat disambungkan dengan data pada Pusdatin.

\section{Keterbatasan Penelitian}

Beberapa kendala yang ditemukan pada penelitian ini diantaranya adalah, data Indeks Keluarga Sehat (IKS) belum sesuai dengan kenyataan, misalnya data pada catatan IKS keluarga adalah keluarga dengan kategori

\section{DAFTAR PUSTAKA}

Ade, M., Doulamis, N., Wagle, S. S., \& Ullah, M. G. (2011). TeleHealth: Healthcare technologies and teleHealth emergency (The) system. In 2011 2nd International Conference on Wireless Communication, Vehicular Technology, Information Theory and Aerospace \& Electronic Systems Technology (Wireless VITAE) (pp. 1-4). IEEE.

Afrianti, F. (2020). Obstacles of the "merah" namun pada kenyataan di Lapangan keluarga tidak ada masalah dengan 12 indikator penilaian IKS. Sehingga kebutuhan keluarga pada aplikasi ini tidak begitu urgent, masyarakat/keluarga justru lebih banyak tertarik dengan layanan pengobatan yang tidak ada dalam program PIS-PK. Berhubungan dengan hal tersebut penggunaan SIPISPeKa menjadi tidak optimal, sehingga penilaian juga cenderung bias.

Penelitian hanya menilai kelayakan SIPISPeKa ditinjau dari 4 unsur penilaian, belum melihat apakah dengan penggunaan SIPISPeKa efektif untuk tahapan intervensi PIS-PK dalam meningkatan Indeks Keluarga Sehat (IKS), oleh karena itu perlu dilakukan penelitian/kajian lebih lanjut, apakah SIPISPeKa efektif meningkatkan IKS.

\section{SIMPULAN}

Desain model aplikasi telehealth atau SIPISPeKa merupakan media berbasis web dengan pengguna aplikasi terdiri dari: super admin, pemegang program dan kepala keluarga, pengguna login dengan username dan password masing-masing.

SIPISPeKa sebagai media telenursing/telehealth dinilai layak dinilai dari 4 aspek penilaian yaitu: kaidah media telehealth, tata kelola, media komunikasi berbasis web dan relevansi dengan program PIS-PK oleh ahli media dan ahli PISPK, namun dari penilaian user (pemegang program dan kepala keluarga dinilai tidak layak dari aspek media sistem informasi berbasis web dan relevansi dengan program PISPK.

Berdasarkan komentar dan saran dari pemegang validator, pemegang program/petugas Puskesmas (user 1), dan Masyarakat (user 2), perlu adanya penambahan fitur pada aplikasi dan menyarankan agar aplikasi mudah digunakan serta berbasis android.

Implementation of the Healthy Indonesia Program with Family Approach (PIS-PK). In 2nd Sriwijaya International Conference of Public Health (SICPH 2019) (pp. 188197). Atlantis Press.

Ameen, J., Coll, A. M., \& Peters, M. (2005). Impact of tele-advice on community nurses' knowledge of venous leg ulcer care. Journal of Advanced Nursing, 50(6), 583-594. https://doi.org/10.1111/j.1365- 
2648.2005.03442.x

Astuti, W. P., Wibawanto, H., \& Khumaedi, M. (2015). Pengembangan instrumen penilaian unjuk kerja praktik perawatan kulit wajah berbasis kompetensi di Universitas Negeri Semarang. Innovative Journal of Curriculum and Educational Technology, 4(1).

Bauer, K. A. (2001). A Survey of Ethical Issues. Cambridge Quarterly of Healthcare Ethics, 137-146.

Binks, S., \& Benger, J. (2007). Tele-education in emergency care. Emergency Medicine Journal, 24(11), 782-784. https://doi.org/10.1136/emj.2005.033795

Bohnenkamp, S. K., Mcdonald, P., Lopez, A. M., Krupinski, E., \& Blackett, A. (2004). Traditional Versus Telenursing Outpatient Management of Patients With Cancer With New Ostomies. Oncology Nursing Forum, 31(5), 1005-1011.

Cottrell, E., Cox, T., O'Connell, P., \& Chambers, R. (2015). Implementation of simple telehealth to manage hypertension in general practice: A service evaluation. BMC Family Practice, 16(1), 1-9. https://doi.org/10.1186/s12875-015-0301-2

Putri, F. P., \& Kurniasari, F. (2019). Sistem Informasi Layanan Puskesmas Berbasis Web. Ultimatics: Jurnal Teknik Informatika, 11(2), https://doi.org/10.31937/ti.v11i2.1457

Firdaus, A. J. A., Pramono, D., \& Purnomo, W. (2020). Pengembangan Sistem Informasi UPT Kalibrasi Dinas Kesehatan Kabupaten Malang Berbasis WEB. Jurnal Sistem Informasi, Teknologi Informasi, Dan Edukasi Sistem Informasi, 1(1), 2334. https://doi.org/10.25126/justsi.v1i1.3

Gott, M. (1995). Telematics For Health (1st Edition). CRC Press.

Hartford, K. (2005). Telenursing and patients' recovery from bypass surgery. Journal of Advanced Nursing, 50(5), 459-468. https://doi.org/10.1111/j.13652648.2005.03427.x

Istifada, R., Sukihananto, S., \& Laagu, M. A. (2017). Pemanfaatan Teknologi Telehealth pada Perawat di Layanan Homecare. Nursing Current, 5(1), 51-61.

Jerant, A. F., Azari, R., Martinez, C., \& Nesbitt, T. S. (2003). A randomized trial of telenursing to reduce hospitalization for heart failure: patient-centered outcomes and nursing indicators. Home health care services quarterly, 22(1), 1-20.

Jönsson, A. M., \& Willman, A. (2008).
Implementation of telenursing within home healthcare. Telemedicine and $E$ Health, 14(10), 1057-1062. https://doi.org/10.1089/tmj.2008.0022

Kementerian Kesehatan RI. (2019). Buku pedoman manajemen penyakit tidak menular. Jakarta.

Kementerian Kesehatan RI. (2017). Petunjuk Teknis Aplikasi Keluarga Sehat. 1-60. Jakarta.

Kementerian Kesehatan RI. (2017). Buku Monitoring dan Evaluasi PIS-PK. Vol. 1, pp. 1-85. Jakarta.

Kementerian Kesehatan RI. (2018). Program Indonesia Sehat dengan Pendekatan Keluarga-PISPK. Jakarta. http://pispk.kemkes.go.id/id/

McManus RJ, Mant J, Bray EP, Holder R, Jones MI, Greenfield S, Kaambwa B, Banting M, Bryan S, Little P, Williams B, H. F. (2010). Telemonitoring and selfmanagement in the control of hypertension (TASMINH2): a randomised controlled trial. Lancet, 376(9736), 163-172. https://www.thelancet.com/journals/lancet/ article/PIIS0140-6736(10)60964-6/fulltext

McSwain, S. D., Chuo, J., Draddy, C. M. H., \& Schinasi, D. (2019). Telemedicine in the Pediatric ICU. Telemedicine in the ICU (pp. 243-253). Springer, Cham.

Mcwilliam, Godfrey, M., Stewart, M., Mitchell, J., Cohen, I., \& Godfrey, B. (2008). Evolving the Delivery of Acute Care Services in the Home Evolving the Delivery of Acute Care Services in the Home. Home Health Care Services Quarterly Abstract., 1424(February 2015), 37-41. https://doi.org/10.1300/J027v22n01

Munandar, M. H., \& Masrizal, M. (2020). Sistem Informasi Pelayanan Puskesmas Tanjung Medan Kab. Labuhanbatu Selatan Berbasis Web. Jurnal Informatika, 8(2), 59-64. https://doi.org/10.36987/informatika.v8i2. 1426

Muzammil, S. (2020). Telehealth: Is It Only for the Rural Areas? A Review of Its Wider Use. Telehealth and Medicine Today, 5, 116. https://doi.org/10.30953/tmt.v5.162

Napitupulu, D. B. (2006). Perancangan Sistem Informasi Pelatihan Koperasi Uji Mutu Berbasis Web. Jurnal Sistem Informasi MTI-UI, 4(1), 67-71.

Nugroho, W., \& Saleh, F. (2012). Perancangan Media Komunikasi Berbasis Web Untuk Pembelajaran. Jurnal Sistem Informasi, 5(2), 100. https://doi.org/10.21609/jsi.v5i2.268

Power, L., Jackson, L., \& Dunnett, S. (2018). 
Developing a Sensor based Homecare System - The Role of Bluetooth Low-Energy in Activity Monitoring. Proceedings of the 11th International Joint Conference on Biomedical Engineering Systems and Technologies. https://doi.org/10.5220/0006722305980606

Putra, I. D., \& Hasana, U. (2020). Analisis Hubungan Sikap dan Pengetahuan Keluarga dengan Penerapan Program Indonesia Sehat dengan Pendekatan Keluarga. Jurnal Endurance, 5(1), 13. https://doi.org/10.22216/jen.v5i1.4282

Pressman, R. (1996). Software process impediment. IEEE software, 13(5), 16-17.

Saputra, Tatang, Kurniadi, E. (2019). Sistem Informasi Rekam Medis Pasien Rawat Jalan di UPTD Puskesmas Kuningan Berbasis Web. Jurnal Nuansa Informatika, 13, 19-23.

Sensuse, D. I., \& Prayoga, S. H. (2012). Analisis Usability Pada Aplikasi Berbasis Web Dengan Mengadopsi Model Kepuasan
Pengguna (User Satisfaction). Jurnal Sistem Informasi, 6(1), 70. https://doi.org/10.21609/jsi.v6il.278

Susanto, E. S., \& Fu'ani, M. Z. A. (2020). Rancang Bangun Sistem Informasi Holticultural Olat Maras Berbasis Web: Rancang Bangun Sistem Informasi Holticultural Olat Maras Berbasis Web. Jurnal Informatika, Teknologi dan Sains, 2(4), 208-213.

Udo Richter, Anika Reichert, Dominika Urbanski, Stefanie Scholz, V. E. A. (2014a). Die Homecare-Versorgung in Deutschland. 5-14.

Udo Richter, Anika Reichert, Dominika Urbanski, Stefanie Scholz, V. E. A. (2014b). Homecare und Entlassmanagement. 37-52. https://doi.org/32745/9783954663712-3

West, H. (2020). Telemedicine in Oncology: Delivering on an Overdue Promise in the COVID-19 Era. Frontiers in Oncology, 10(September), 1-4. https://doi.org/10.3389/fonc.2020.578888 